\title{
LARYNGOLOGY
}

\section{Modified Isshiki's arytenoid adduction without separating cricothyroid and cricoarytenoid joints}

\author{
Intervento di adduzione aritenoidea sec. Isshiki modificata, \\ senza separazione cricotiroidea e cricoaritenoidea
}

\author{
Eiji Yumoto ${ }^{1,2}$, Tetsuji Sanuki ${ }^{3}$, Yoshihiko Kumai², Narihiro Kodama ${ }^{2,4}$ \\ ${ }^{1}$ Department of Otolaryngology, Asahino General Hospital 12-10, Murozono-cho, Kita-ku, Kumamoto, Japan; ${ }^{2}$ Department of \\ Otolaryngology-Head and Neck Surgery, School of Medicine, Kumamoto University 1-1-1, Honjo, Chuo-ku, Kumamoto, Japan; \\ ${ }^{3}$ Department of Otolaryngology-Head and Neck Surgery, School of Medicine Nagoya City University 1, Kawasumi, Mizuho-cho, Mizuho- \\ ku, Nagoya, Japan; ${ }^{4}$ Department of Rehabilitation, Kumamoto Health Science University 325, Izumi-cho, Kita-ku, Kumamoto, Japan
}

\begin{abstract}
SUMMARY
Modified methods of arytenoid adduction (AA) have been reported to keep the cricothyroid (CT) joint intact. However, postoperative laryngeal oedema and long-term vocal function have not been compared with those after AA with CT joint separation. We refined AA to combine it with nerve-muscle pedicle (NMP) flap transfer for preservation of the CT joint. Eight patients with unilateral laryngeal paralysis underwent the procedure (Group 1). Postoperative oedema at membranous vocal fold (MVF), arytenoid mound (AM) and pyriform sinus (PS) was assessed using a 4-point ordinal scale: none (0) to severe (3). Laryngeal oedema in Group 1 was compared with that of 19 patients who had AA with CT joint separation (Group 2). Maximum phonation time (MPT), jitter and voice handicap index-10 (VHI-10) were measured before surgery and one year postoperatively. Vocal function in Group 1 was compared with 58 patients who underwent AA + NMP flap transfer with CT joint separation (Group 3). The degree of oedema from postoperative days 1 to 6 in Group 1 was relatively invariable: $1.2 \sim 1.6$ at MVF, 1.3 1.7 at AM, and 1.4 1.7 at PS. The scores at 3 and 4 days postoperatively at MVF and PS in Group 1 were significantly lower than in Group $2(\mathrm{P}=0.0032$ and 0.0317 at day 3, and 0.0224 and 0.0182 , at day 4, respectively). The degree of oedema at day 3 at AM in Group 1 was significantly less than in Group $2(\mathrm{P}=0.0260)$. One year after surgery, there were no significant differences in MPT, jitter and VHI-10 between Groups 1 and 3 ( $P=0.660,0.111$ and 0.556 , respectively). Preservation of the CT joint might be beneficial in reducing the maximum degree of laryngeal oedema after AA. Vocal function after AA + NMP flap transfer with CT joint preservation is comparable to that after AA + NMP flap transfer with CT joint separation.
\end{abstract}

KEY WORDS: modified arytenoid adduction, preservation of the cricothyroid and cricoarytenoid joints, location of the muscular process, postoperative oedema, vocal function

\section{RIASSUNTO}

Gli interventi modificati di adduzione aritenoidea (AA) sono finalizzati a preservare l'integrità dell'articolazione cricotiroidea. Non ci sono tuttavia studi comparativi che confrontino tali metodiche con interventi in cui vi sia la separazione cricotiroidea in termini di edema laringeo postoperatorio e funzione fonatoria a lungo termine. In questo studio si valuta un intervento di AA con allestimento di lembo peduncolato neuromuscolare (+ NMP) e preservazione dell'articolazione cricotiroidea. Sono stati valutati otto pazienti con paresi cordale monolaterale sottoposti a tale procedura (Gruppo 1). È stato valutato l'edema post operatorio a livello delle corde vocali, cappucci aritenoidei e seni piriformi con una scala, da 0 a 3 (0: nessun edema - 3: edema grave). Il gruppo controllo (Gruppo 2) è rappresentato da 19 pazienti sottoposti a AA con separazione dell'articolazione cricotiroidea. Il tempo massimo di fonazione (MPT), il jitter e il voice hadicap index (VHI) sono stati misurati prima e 1 anno dopo la chirurgia. I risultati funzionali fonatori del Gruppo 1 sono stati comparati con quelli di un gruppo controllo formato da 58 pazienti sottoposti a AA + NMP (Gruppo 3). L'edema a livello delle corde vocali, cappucci aritenoidei e seni piriformi del
Received: March 21, 2019

Accepted: September 8, 2019

Correspondence

Eiji Yumoto

Department of Otolaryngology, Asahino General Hospital 12-10, Murozono-cho, Kita-ku, Kumamoto, Japan $861-8072$

Fax +81963437570

E-mail: yu6167@asahino.or.jp

Funding

None.

Conflict of interest

The Authors declare no conflict of interest.

How to cite this article: Yumoto E, Sanuki T, Kumai Y, et al. Modified Isshiki's arytenoid adduction without separating cricothyroid and cricoarytenoid joints. Acta Otorhinolaryngol Ital 2020;40:99-105. https://doi. org/10.14639/0392-100X-N0183

() Società Italiana di Otorinolaringoiatria e Chirurgia Cervico-Facciale

\section{(c) (1) () $)$}

This is an open access article distributed in accordance with the CC-BY-NC-ND (Creative Commons Attribution-NonCommercial-NoDerivatives 4.0 International) license. The article can be used by giving appropriate credit and mentioning the license, but only for non-commercial purposes and only in the original version. For further information: https:// creativecommons.org/licenses/by-nc-nd/4.0/deed.en 
Gruppo 1 è risultato relativamente stabile dal primo al sesto giorno post operatorio. L'edema a livello delle corde vocali e seni piriformi nel Gruppo 1, a 3 e 4 giorni dalla chirurgia è risultato inferiore rispetto al Gruppo 2. Ad un anno dopo la chirurgia, non sono risultate differenze in termini di MPT, Jitter e VHI fra il Gruppo 1 e il Gruppo 3. La preservazione dell'articolazione cricotiroidea può risultare vantaggiosa nel ridurre l'edema laringeo post operatorio dopo AA. La funzione vocale dopo AA + NMP con preservazione o separazione dell'articolazione cricotiroidea sono comparabili.

PAROLE CHIAVE: adduzione aritenoidea modificata, preservazione dell'articolazione cricotiroidea e cricoaritenoidea, processo vocale, edema post operatorio, funzione vocale

\section{Introduction}

Arytenoid adduction (AA), often combined with type I thyroplasty, has been applied to improve hoarse voice in patients with unilateral vocal fold paralysis. The original method reported by Isshiki et al. ${ }^{1}$ included separation of the cricothyroid (CT) joint to open the paraglottic space, as well as opening of the cricoarytenoid (CA) joint for identification of the muscular process of the arytenoid cartilage.

Opening of the CA joint destabilises the arytenoid cartilage and predisposes its prolapse anteriorly with suture traction ${ }^{2,3}$. Thus, several modifications to avoid CA joint opening have been reported ${ }^{4,5}$. We also did not open the CA joint while basically following Isshiki's method ${ }^{6}$. Recently, AA without CA joint separation has prevailed. On the other hand, Zeitels et al. observed that, after CT joint separation, the thyroid lamina became retrodisplaced with relation to the cricoid, resulting in the vocal fold shortened and reduction of the thyroarytenoid muscle tension ${ }^{7}$. The routes to locate the muscular process reported by Maragos ${ }^{4}$ and Tokashiki et al. ${ }^{5}$ also avoided CT joint separation. However, these authors did not assess postoperative laryngeal oedema and did not compare vocal outcomes of their methods with that of AA with separation of the CT joint ${ }^{4,5}$.

We have modified Isshiki's method to perform AA by preserving the $\mathrm{CT}$ as well as $\mathrm{CA}$ joints. In the present paper, we describe a key technique of our refined AA procedure and preliminary evaluation of postoperative laryngeal oedema and vocal function to compare them with those following AA with separation of the CT joint.

\section{Materials and methods}

This study was approved by the institutional review board of Kumamoto University Hospital.

\section{Surgical procedures}

The difference of the surgical procedure from our previous report ${ }^{6}$ is that the CT joint was not separated. Isshiki's original method was that, after separating the CT joint and the thyrohyoid ligament, the thyroid lamina is rotated as a whole to open the paraglottic space ${ }^{1}$. In our modified method, following separation of the thyrohyoid ligament, the pyriform sinus (PS) mucosa and inner perichondrium are elevated from the superior cornu and thyroid ala medially and inferiorly. Next, the thyroid ala is rotated anteriorly from the cranial side to open the paraglottic space for location of the muscular process (Fig. 1). Creation and transfer of a nerve-muscle pedicle (NMP) flap was performed as reported previously ${ }^{6}$. Intravenous hydrocortisone sodium succinate $(500 \mathrm{mg})$ was administered. Intravenous steroids were given at $300 \mathrm{mg}$ on postoperative day (POD) 1 and tapered down to $100 \mathrm{mg}$ on PODs 2 to 3, with minor dose modifications depending on the patient's baseline and perioperative airway anatomy.

\section{Subjects}

Nine consecutive patients underwent AA combined with NMP flap transfer between May 2014 and July 2016 at Kumamoto University Hospital. One patient received a tracheostomy after the operation because of poor pulmonary function and was excluded from the study. Thus, eight patients were enrolled (Group 1).

The degree of oedema at each subsite during the period from POD 1 to 6 in Group 1 patients was compared with that of 19 patients after AA with the CT joint separated (Group 2). The data reported by Narajos et al. ${ }^{8}$ were used because they separated the CT joint to perform AA. Their patients underwent either of AA alone, AA with recurrent laryngeal nerve-ansa cervicalis nerve anastomosis, or AA with NMP flap transfer. Vocal function of Group 1 patients

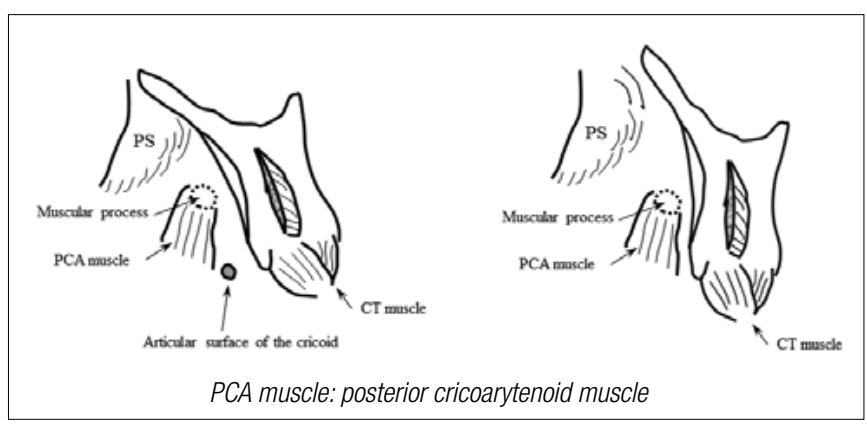

Figure 1. Surgical approach to locate the muscular process of the arytenoid (right side). Left: after separating the cricothyroid (CT) joint and thyrohyoid ligament, the thyroid lamina is rotated anteriorly as a whole to open the paraglottic space for location of the muscular process. Right: the CT joint is not separated. Following separation of the thyrohyoid ligament, the pyriform sinus (PS) mucosa and inner perichondrium are elevated from the superior cornu and thyroid ala. Next, the cranial side of the thyroid ala is rotated anteriorly to locate the muscular process. 
was compared with that of 58 patients after AA + NMP flap transfer with CT joint separation (Group 3). They were operated on between July 2002 and April 2014 at Kumamoto University Hospital. The same operator (EY) performed the procedures under general anaesthesia in all patients in Groups 1 to 3. In Group 2, only AA was performed when recurrent laryngeal nerve-ansa cervicalis nerve anastomosis and NMP flap transfer were not feasible. Patients in Groups 1 and 3 were not randomly assigned because Group 1 patients underwent AA + NMP flap transfer after May 2014, while those in Group 3 underwent the operation before April 2014.

\section{Evaluation of postoperative laryngeal oedema}

All recordings were made under videolaryngoscopy using a flexible transnasal videoendoscope (VNL-1171K, EPK-1000; PENTAX, Tokyo, Japan) and fed to a computerised data filing system (Claio; Findex Inc., Tokyo, Japan). Postoperative laryngeal findings were recorded daily from POD 1 to 10. Patients were observed during quiet breathing.

Three experienced laryngologists rated postoperative laryngeal oedema. Each examiner was given a digital versatile disc copy of the postoperative laryngeal recordings. The videolaryngoscopic images without voice signal were ordered randomly by patient and the POD on which the recordings were taken. Each examiner rated postoperative laryngeal oedema at the three subsites; membranous vocal fold (MVF), arytenoid mound (AM), and pyriform sinus (PS). A fourpoint ordinal scale was used to score the degree of oedema as none (0), mild (1), moderate (2), or severe (3) (Tab. I) ${ }^{8}$.

\section{Vocal function measurements}

The vocal function of each patient in Groups 1 and 3 was assessed twice; within two weeks before surgery and one year after surgery. To measure maximum phonation time (MPT), patients were instructed to produce sustained phonation of the vowel /a/ for as long as possible at comfortable pitch and loudness. MPT was measured twice for each patient and the greater value was recorded. Voice recording was performed in a sound-treated room using a digital recorder (Model PMD 670; Marantz, Sagamihara, Japan) connected to a microphone (Model WM-421; Panasonic, Kadoma, Japan). The microphone was held at a distance of $20 \mathrm{~cm}$ from the mouth during recordings. Recording samples of sustained vowel /a/ at comfortable pitch and loudness digitised at $45 \mathrm{kHz}$ through antialiasing filter were stored with a pulsecode modulation format. A stable portion of the vowel of 0.5 to 1 second duration was trimmed and utilised for acoustic analysis. Jitter, shimmer and noise-to-harmonics ratio were obtained with the use of Multi-Dimensional Voice Program Model 5105 (version 3.1.7; KayPentax, Lincoln Park, NJ). Further, all patients in Group 1 were asked to rate each of the 10 statements in a validated Japanese version ${ }^{9}$ of VHI-10 query sheet on a scale of 0 to $4(0=$ strongly disagree, $4=$ strongly agree), for a possible worst total score of 40 . Since we started to evaluate patients' subjective difficulty in their daily life due to unilateral vocal fold paralysis in November 2008, 40 of 58 Group 3 patients were asked to fill out a VHI-10 query sheet.

\section{Statistical analysis}

Spearman correlation coefficients were calculated to examine reliability of the three judges' evaluations. Wilcoxon signed rank test was used to examine whether there was a significant difference in the degree of oedema at each subsite according to the postoperative time course. Wilcoxon signed rank test was also used to examine changes in VHI-10 during a follow-up period in Groups 1 and 3. Paired t test was used to examine changes in MPT and jitter measurements during follow-up.

The degree of oedema at each subsite during the period from POD 1 to 6 was compared with that of Group 2 (AA with the CT joint separated); Mann-Whitney U test was used. Measurements of MPT and jitter, and VHI-10 scores before operation and one year after the operation were compared between Groups 1 and 3, respectively, using MannWhitney $U$ test because the number of patients in Group 1 was small. The significance level was set at $\mathrm{P}<0.05$.

\section{Results}

Table II presents the demographic characteristics of Group 1 including age, gender, side and cause of paralysis, history

Table I. Videolaryngoscopic scoring scheme for the degree of laryngeal oedema at three subsites.

$\begin{array}{cccc}\text { Score } & \text { Membranous vocal fold } & \text { Arytenoid mound } & \text { Pyriform sinus } \\ 0 & \text { No oedema } & \text { No oedema } & \text { No oedema } \\ 1 & \text { Confined oedema } & \text { Confined oedema } & \text { Visible space } \\ & \text { (no contact with the opposite vocal fold) } & \text { (only to the affected arytenoid mound) } & \text { (but more shallow than the unaffected side) } \\ 2 & \text { Expanding oedema } & \text { Expanding oedema } & \text { Some visible space } \\ & \text { (contacts } \leq \text { one half of the opposite vocal fold) } & \text { (extends to the aryepiglottic fold) } & \text { (mucosa obliterates } \geq \text { one half of the pyriform sinus) } \\ 3 & \text { Expanding oedema } & \text { Expanding oedema } & \text { No visible space }\end{array}$


Table II. Patient demographics in Group 1.

\begin{tabular}{ccccccc} 
No. & Age & Gender & Side & Cause of paralysis & History of neck surgery & Duration of paralysis \\
1 & 53 & F & L & Post heart op & Absent & 11 months \\
2 & 77 & F & L & Idiopathic & Absent & unknown \\
3 & 34 & F & L & Post heart op & Absent & 32 years \\
4 & 74 & M & L & Idiopathic & Absent & 9 months \\
5 & 30 & M & L & Post aortic aneurysm op & Absent & 9 months \\
6 & 54 & F & R & Epithelioid angioendothelioma in the internal jugular vein & Present & 3 months \\
7 & 64 & F & L & Clipping of intracranial aneurysm & Present & 8 months \\
8 & 14 & M & L & Post-intubation & Absent & 71 months \\
\hline
\end{tabular}

F: female; M: male; L: left, R: right.

of neck surgery and duration of paralysis until surgery. No postoperative complications, such as haematoma or wound infection, were encountered during hospitalization. No patients complained of dyspnoeic sensation and no episodes of airway obstruction requiring a tracheostomy occurred. Table III presents demographic characteristics of the patients in Groups 2 and 3 including age, gender, side and cause of paralysis, and duration of paralysis until surgery. Because duration of paralysis until surgery ranged widely with a skewed distribution in the Groups 2 and 3 patients, mean and median values together with the ranges were listed.

Spearman correlation coefficients of three pairs of examiners for scoring the degree of oedema at each laryngeal subsite in Group 1 patients ranged between 0.679 and $0.746(\mathrm{P}<0.0001)$. Since the scores of the three judges agreed significantly, the

Table III. Patients demographics in Groups 2 and 3.

\begin{tabular}{lcc} 
& Group 2 & Group 3 \\
Number of patients & 19 & 58 \\
Age (average \pm SD, range) & $56.0 \pm 15.3$, & $59.3 \pm 13.3$ \\
& $32 \sim 75$ & $22 \sim 82$ \\
Gender (male/female) & $14 / 5$ & $28 / 30$ \\
Side of paralysis (left/right) & $16 / 3$ & $44 / 14$ \\
Duration of paralysis (months) & & \\
Mean (range) & $41.0(4 \sim 360)$ & $35.0(1 \sim 612)$ \\
Median & 11.0 & 11.5 \\
Cause of paralysis: & & \\
latrogenic: & & \\
Thyroid cancer & 7 & 17 \\
Graves' disease & & 1 \\
Vagal nerve neurinoma of neck & & 2 \\
Subarachnoid haemorrhage & & 4 \\
Meningioma & 2 & 1 \\
Mediastinal tumour & 3 & 6 \\
Aortic aneurysm & & 11 \\
Heart valvular disease & 1 & 8 \\
Lung cancer & 4 & 0 \\
Esophageal cancer & & \\
Non-iatrogenic: & & 6 \\
Pulmonary tuberculosis & 2 & \\
ldiopathic & & \\
\hline SD: & &
\end{tabular}

SD: standard deviation. degree of oedema was assessed in terms of the mean of the three scores. Figure 2 illustrates time course of laryngeal oedema at each subsite following AA with the CT and CA joints preserved (Group 1, indicated by continuous line) and following AA with the CT joint separated ${ }^{8}$ (Group 2, indicated by dotted line). The degree of oedema at each subsite from PODs 1 to 6 in Group 1 was relatively invariable: 1.2 1.6 at MVF, 1.3 1.7 at AM, and 1.4 1.7 at PS. Significant decreases in the degree of oedema at each subsite were detected when the scores for degree of oedema at PODs 1 to 6 were compared with those at POD 10.

The scores at PODs 3 and 4 at MVF in Group 1 were significantly lower than those in Group $2(\mathrm{P}=0.0032$ and 0.0317 , respectively). The degree of oedema at POD 3 at AM in Group 1 was also significantly less than that in Group 2 $(\mathrm{P}=0.0260)$. Furthermore, the scores at PODs 3 and 4 at PS in Group 1 were significantly lower than those in Group 2 $(\mathrm{P}=0.0224$ and 0.0182 , respectively).

Figure 3 illustrates changes in MPT, jitter and VHI-10 before surgery and one year after surgery in Groups 1 (dotted bar) and 3 (oblique-lined bar). MPT measurements and VHI-10 scores in Group 1 improved one year after surgery, but, the improvements did not reach significance. Jitter in Group 1 showed a significant improvement after surgery $(\mathrm{P}=0.01)$, and MPT, jitter and VHI-10 showed a significant improvement after surgery in Group 3 ( $\mathrm{P}<0.001$ in all parameters).

Preoperatively, differences in jitter and VHI-10 between Groups 1 and 3 were not significant $(\mathrm{P}=0.182$ and 0.156 , respectively), and MPT in Group 3 was significantly smaller than in Group $1(\mathrm{P}=0.041)$. One year after surgery, there were no significant differences in MPT, jitter and VHI-10 between Groups 1 and $3(\mathrm{P}=0.660,0.111$ and 0.556 , respectively).

\section{Discussion}

Arytenoid adduction often combined with type I thyroplasty reported by Isshiki et $\mathrm{al}^{1}$ has been the prevailing treatment for paralytic dysphonia. Their method included separation of the $\mathrm{CT}$ joint to open the paraglottic space, as well as opening of 
the CA joint for identification of the muscular process of the arytenoid cartilage. Preservation of the CA joint contributes to relatively stable support of the arytenoid and impedes its anterior shift. Additionally, CT joint preservation avoid posterior displacement of the thyroid lamina ${ }^{7}$.

Postoperative laryngeal oedema is a major complication of AA. The frequency of the necessity of tracheostomy after AA ranged between $1.6 \%$ and $4.2 \%{ }^{10,11}$. It has been believed that postoperative oedema of the AM relates directly to the precision and extent of management around the CA joint and length of time to perform it ${ }^{12}$. However, relation of the operative management around the CT joint to laryngeal oedema has not been evaluated.

The superior thyroid artery has a branch that projects to the larynx (superior laryngeal artery (SLA)) and then runs inferiorly to the thyroid gland and CT muscle. Iimura et al. further studied the branches of the SLA (Fig. 4) ${ }^{13}$. Its first branch, the superoposterior branch, projects to the aryepiglottic fold, while the anterior branch goes to the front wall of the larynx, the medial posterior branch projects to the posterior wall of the arytenoid and front wall of the pharynx, the medial branch runs medially to the laryngeal wall and, finally, the SLA separates into anteroinferior and posteroinferior branches. The two final divisions project to the lower part of the anterior and posterior walls of the larynx. They also reported that the superoposterior and medial posterior branches show marked meandering in their courses. In addition, some branches anastomose one another. In the process of exposure and separation of the $\mathrm{CT}$ joint during AA, the CT branch of the superior thyroid artery and medial posterior, anteroinferior and posteroinferior branches of the SLA might be injured. Such injuries could be a factor which cause exacerbation of laryngeal oedema. Thus, preservation of the CT joint might be beneficial in reducing the maximum degree of laryngeal oedema after AA. Actually, in Group 1, the degree of oedema at each subsite was significantly lower at PODs 3 and 4 versus those in Group 2 (Fig. 2). However, the number of Group 1 patients was too small to draw any definitive conclusion regarding the effect of AA with $\mathrm{CT}$ joint preservation on postoperative oedema.

Vocal function assessed with the use of MPT, jitter and VHI10 did not show a significant difference between Groups 1 and 3 at one year after surgery. Thus, vocal function one year after surgery in Group 1 is highly comparable to that of Group 3.

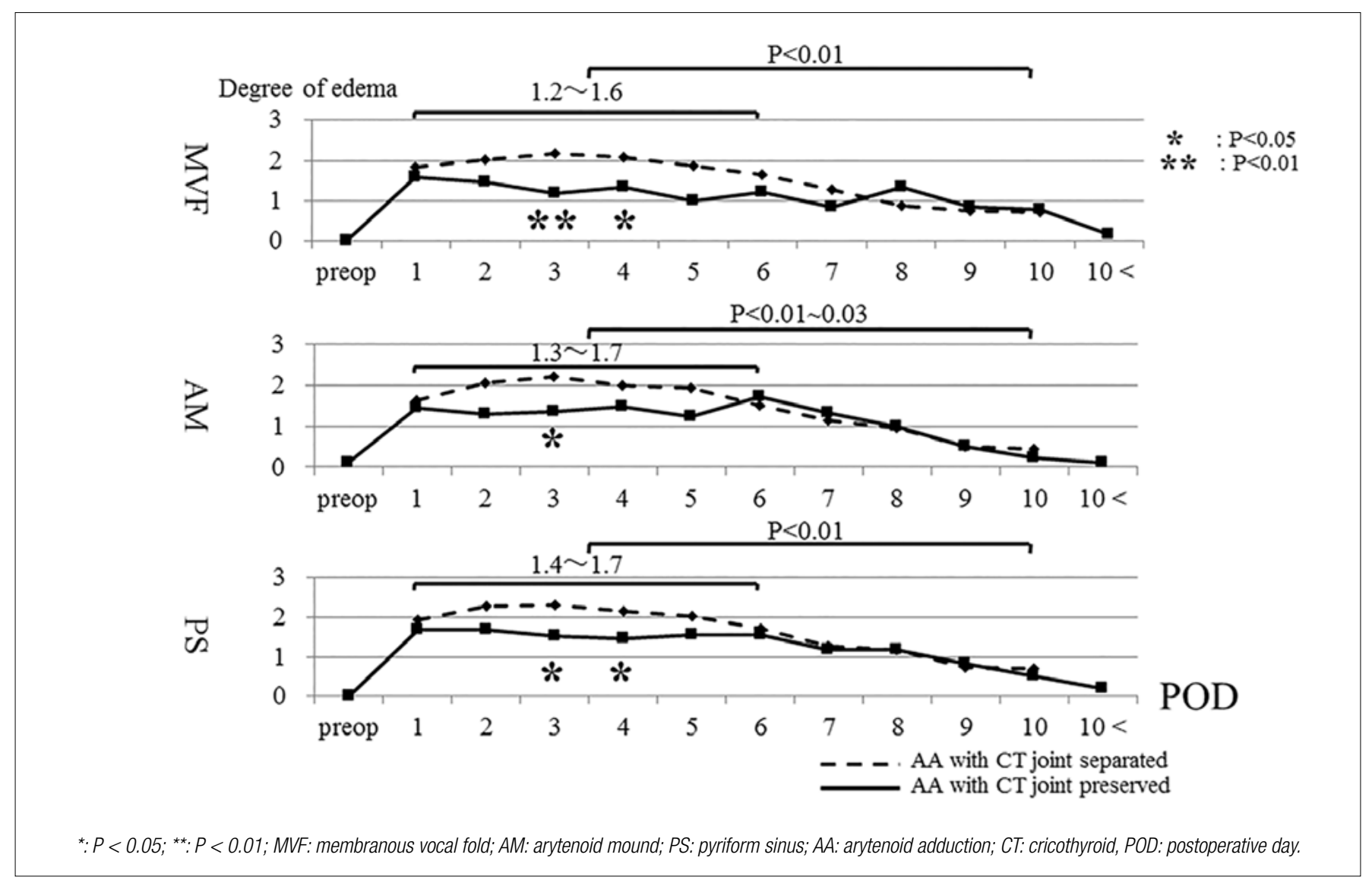

Figure 2. Time course of laryngeal oedema at each subsite following AA with the CT joint preserved (Group 1, continuous line) and following AA with the CT joint separated (Group 2, dotted line), as reported in our previous paper (from Narajos et al., $2012^{8}$ ). 

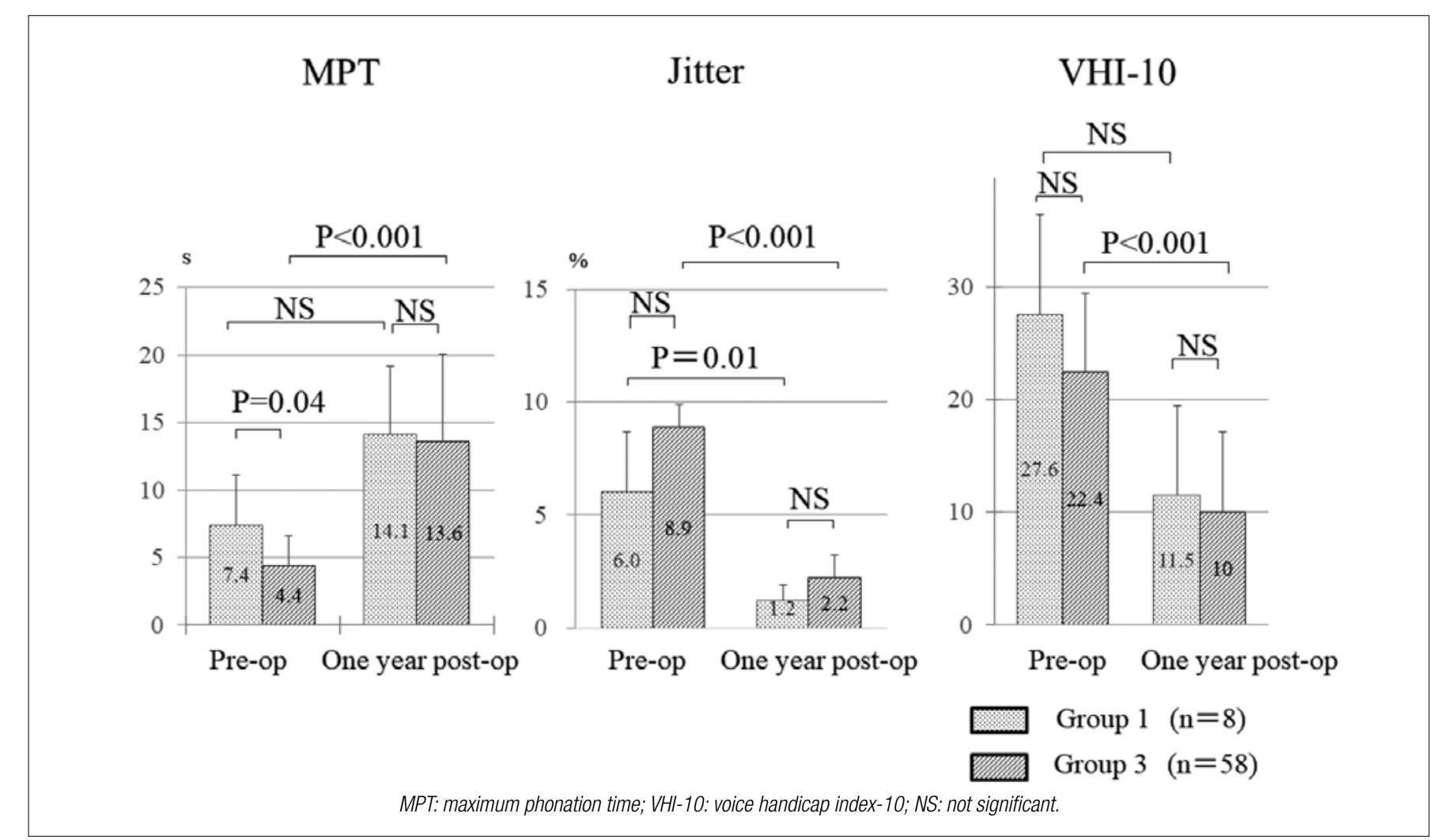

Figure 3. Changes in MPT, jitter and VHI-10 before surgery and one year after surgery in Group 1 (AA + NMP transfer with the CT joint preserved) and Group 3 (AA + NMP transfer with the CT joint separated). Dotted bars represent measurements in Group 1 and oblique-lined bars represent measurements in Group 3. The number in a bar shows the mean value of each parameter.

Although there was no significant difference, jitter in Group 1 was nearly half that of Group 3. In addition, as reported by Kodama et al. ${ }^{14,15}$ MPT, jitter and VHI-10 after AA combined with NMP flap transfer continued to improve over the course of 2 years postoperatively. Therefore, vocal function after AA without separation of the CT joint might continue to improve over a 2-year period.

Since Maragos reported the "Posterior window approach"

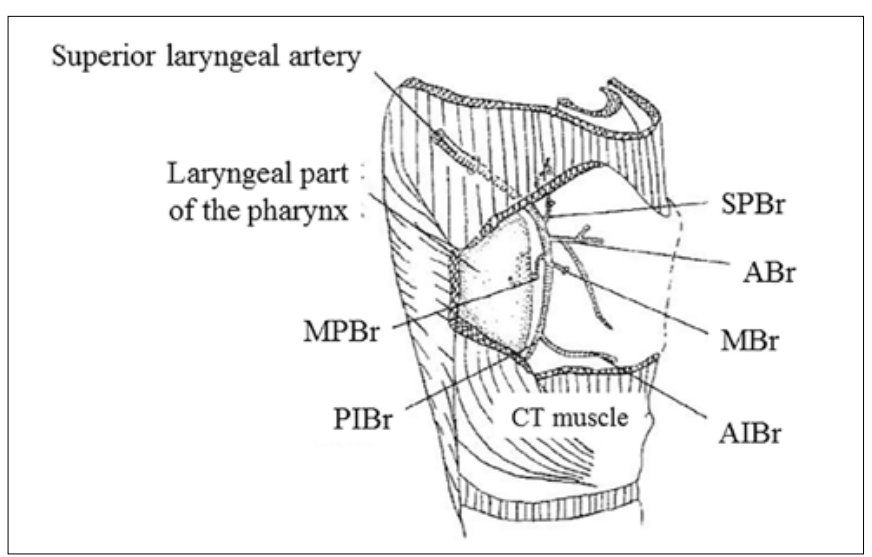

Figure 4. Distribution of the six intralaryngeal branches of the superior laryngeal artery (from limura et al., $2004{ }^{13}$ ). to reach the muscular process ${ }^{4}$, this approach has become commonplace in the United States to perform AA ${ }^{16}$. The posterior window was a half circle with radius of $10 \mathrm{~mm}$ and the centre of the circle was set at the intersection of the posterior border of the thyroid ala and the horizontal line at the estimated vocal fold level. When AA through the posterior window approach is combined with type I thyroplasty, it is preferable to make a window size small enough to maintain the framework of the thyroid ala. Actually, Maragos reported that three patients had fractures of either the inferior cornu or the lateral ala secondary to forward retraction on the thyroid ala when combined with type I thyroplasty ${ }^{4}$. McCulloch et al inserted Gore-Tex from below the thyroid cartilage when AA through the posterior window approach is combined with type I thyroplasty ${ }^{16}$. In addition to type 1 thyroplasty, injection laryngoplasty is also a useful adjunct after AA to augment the paralysed vocal fold. Kimura et al. reported significant improvements in vocal function with collagen injection for those who did not achieve satisfactory glottal competence with AA alone ${ }^{17}$. They stated that collagen injection has the advantage of being minimally invasive outpatient office procedure over type 1 thyroplasty.

When AA is combined with NMP flap transfer, a window 
is opened in the thyroid ala to expose the thyroarytenoid muscle. The size of the window ranges $10-12 \mathrm{~mm}$ in a horizontal direction and 5-7 $\mathrm{mm}$ in a vertical direction. The medial edge of the window is set 5-7 mm laterally from the midline ${ }^{6}$. Hiramoto studied anatomy of the thyroid cartilage using 28 male and 23 female adult larynges in the Japanese population ${ }^{18}$. The horizontal length of the thyroid ala at the vocal fold level was reported to range from $29 \mathrm{~mm}$ to $44 \mathrm{~mm}$ with a mean of $37 \mathrm{~mm}$ in men and from $24 \mathrm{~mm}$ to $32 \mathrm{~mm}$ with a mean of $28 \mathrm{~mm}$ in women ${ }^{18}$. Therefore, the posterior window approach is not an appropriate route to locate the muscular process while keeping the framework of the thyroid ala intact when AA is combined with NMP flap transfer.

Whether or not AA with the CT joint preserved is feasible in all patients remains to be clarified. We were able to perform AA without separation of the CT joint in all subjects in the present series, including two who had a history of neck surgery on the paralysed side. However, it is highly likely that cicatricial tissue interferes with the location of the muscular process unless the CT joint is separated. Moreover, the thyroid laminae in the male larynx often make a steep angle with each other, and separation of the CT joint might be required for location of the muscular process. Therefore, further studies with a greater number of patients are necessary to confirm the preliminary results of the present study.

\section{Conclusions}

We modified Isshiki's method to perform AA by preserving the $\mathrm{CT}$ as well as CA joints. In our method of AA combined with NMP flap transfer, it is essential to elevate the inner perichondrium from the superior cornu and thyroid ala towards medially and inferiorly. Next, the thyroid ala is rotated anteriorly from the cranial side to open the paraglottic space for location of the muscular process. Preservation of the CT joint might be beneficial in reducing the maximum degree of laryngeal oedema after AA. Vocal function one year after AA + NMP flap transfer with the CT joint preserved is comparable to that after AA + NMP flap transfer with the CT joint separated. This is the first report to suggest the relation of the operative management around the CT joint to postoperative laryngeal oedema. Further studies with a larger number of patients are required to better assess the significance of preservation of the CT joint.

\section{References}

1 Isshiki N, Tanabe M, Sawada M. Arytenoid adduction for unilateral vocal cord paralysis. Arch Otolaryngol 1978;104: 555-8. https://doi. org/10.1001/archotol.1978.00790100009002

2 Hoffman HT, McCulloch TM. Anatomic considerations in the surgical treatment of unilateral laryngeal paralysis. Head Neck 1996;18:174-87. https://doi.org/10.1002/(SICI)10970347(199603/04)18:2<174::AID-HED10>3.0.CO;2-F

3 Slavit DH, Maragos NE. Physiologic assessment of arytenoid adduction. Ann Otol Rhinol Laryngol 1992;101:321-7. https://doi. org/10.1177/000348949210100406

4 Maragos NE. The posterior thyroplasty window: anatomical considerations. Laryngoscope 1999;109:1228-31. https://doi. org/10.1097/00005537-199908000-00008

5 Tokashiki R, Hiramatsu H, Tsukahara K, et al. A "fenestration approach" for arytenoid adduction through the thyroid ala combined with type I thyroplasty. Laryngoscope 2007;117:1882-7. https://doi. org/10.1097/MLG.0b013e3180d09ef9

6 Yumoto E, Sanuki T, Toya Y, et al. Nerve-muscle pedicle flap implantation combined with arytenoid adduction. Arch Otolaryngol Head Neck Surg 2010;136:965-9. https://doi.org/10.1001/archoto. 2010.155

7 Zeitels SM, Hillman RE, Desloge RB, et al. Cricothyoid subluxation: a new innovation for enhancing the voice with laryngoplastic phonosurgery. Ann Otol Rhinol Laryngol 1999;108:1126-31. https://doi.org/10.1177/000348949910801206

8 Narajos N, Toya Y, Kumai Y, et al. Videolaryngoscopic assessment of laryngeal edema after arytenoid adduction. Laryngoscope 2012;122:1104-8. https://doi.org/10.1002/lary.23241

9 Shiromoto O, Ikenaga E. Reliability and validity of VHI (Voice handicap index) and V-RQOL (Voice-related quality of voice): Japanese versions. Japan J Logopedics Phoniatr 2011;52:254-62. https:// doi.org/10.5112/jjlp.52.254

10 Abraham MT, Gonen M, Kraus DH. Complications of type I thyroplasty and arytenoid adduction. Laryngoscope 2001;111:1322-9. https://doi.org/10.1097/00005537-200108000-00003

11 Nito T, Ushio M, Kimura M, et al. Analyses of risk factors for postoperative airway compromise following arytenoid adduction. Acta Otolaryngol 2008;128:1342-7. https://doi. org/10.1080/00016480801958303

12 Zeitels SM, Mauri M, Dailey SH. Adduction arytenopexy for vocal fold paralysis: indications and technique. J Laryngol Otol 2004;118:508-16. https://doi.org/10.1258/0022215041615263

13 Iimura A, Itoh M, Terayama H, et al. Anatomical study of meandering and functions of human intralaryngeal artery. Okajimas Folia Anat Jpn 2004;81:85-92. https://doi.org/10.2535/ofaj.81.85

14 Kodama N, Sanuki T, Kumai Y, et al. Long-term vocal outcomes of refined nerve-muscle pedicle flap implantation combined with arytenoid adduction. Eur Arch Otorhinolaryngol 2015;272:681-8. https://doi.org/10.1007/s00405-014-3418-3

15 Kodama N, Kumai Y, Sanuki T, et al. Arytenoid adduction combined with nerve-muscle pedicle flap implantation or type I thyroplasty. Laryngoscope 2017;127:159-66. https://doi.org/10.1002/lary.26032

16 McCulloch TM, Hoffman HT, Andrews BT, et al. Arytenoid adduction combined with Gore-tex medialization thyroplasty. Laryngoscope 2000;110:1306-11. https://doi.org/10.1097/00005537200008000-00015

17 Kimura M, Nito T, Imagawa $\mathrm{H}$, et al. Collagen injection as a supplement to arytenoid adduction for vocal fold paralysis. Ann Otol Rhinol Laryngol 2008;117:430-6. https://doi. org/10.1177/000348940811700605

18 Hiramoto M. Functional anatomy of the larynx. Practica Oto-RhinoLaryngol 1977;70:177-7. 